\title{
Entre el triunfalismo y la moderación. Los diarios Crónica y El Patagónico de Comodoro Rivadavia durante la guerra de Malvinas
}

\author{
María Laura Olivares \\ FEHR - UNPSJB
}

\section{Resumen}

Este trabajo busca analizar las posturas tomadas por los diarios de la ciudad de Comodoro Rivadavia, provincia del Chubut, durante la Guerra de Malvinas. Para ello se analizarán los editoriales, titulares y noticias aparecidos en los diarios Crónica y El Patagónico, durante los meses de abril, mayo y junio de 1982, proponiendo la hipótesis de que en el marco de censura que imperaba sobre la prensa, el diario Crónica acompañó las versiones oficiales y difundió el espíritu triunfalista del gobierno militar, mientras que el diario El Patagónico fue más moderado y crítico de la situación que se vivía.

Palabras claves

Guerra de Malvinas, prensa, Comodoro Rivadavia, triunfalismo, censura

\begin{abstract}
The purpose of this work is to gain a depth understanding and analyze the different local newspapers' positions on Malvinas War in Comodoro Rivadavia, during the war's period. In fact, editorials, headlines and news of Crónica and El Patagónico newspapers from April to June 1982 will be studied in this context. Moreover, in this context of censure that Media was object, a new hypothesis will be set. Crónica newspaper reflected the spirit of triumphalism of the military government while El Patagónico newspaper was more careful and critical about the real situation of the time.
\end{abstract}

Keywords

Malvinas War, media, Comodoro Rivadavia, triunphalism, censure. 


\section{Entre el triunfalismo y la moderación}

\section{Introducción}

El 2 de abril de 1982 tropas argentinas recuperaron, mediante el uso de la fuerza, sus derechos soberanos sobre las islas Malvinas, Georgias, Sandwich e Islas del Atlántico Sur, ocupadas desde 1833 por Inglaterra. Se iniciaba así la Guerra de Malvinas que finalizaría el 14 de junio de 1982 con la rendición argentina.

Durante la guerra las ciudades costeras de la Patagonia Argentina formaron parte del Teatro de Operaciones del Atlántico Sur ${ }^{1}$, convirtiéndose en escenario continental de los aprestos bélicos. Este fue el caso de la ciudad de Comodoro Rivadavia, ubicada al sur de la provincia del Chubut, la cual vio alterada su vida cotidiana.

Este trabajo busca analizar las posturas tomadas por los dos diarios que se publicaban en la ciudad de Comodoro Rivadavia durante la Guerra de Malvinas. Para ello se analizarán los editoriales, titulares y noticias aparecidos en los diarios Crónica y El Patagónico, durante los meses de abril, mayo y junio de 1982, proponiendo la hipótesis que en el marco de censura que imperaba sobre la prensa, el diario Crónica acompañó las versiones oficiales y difundió el espíritu triunfalista del gobierno militar, mientras que El Patagónico fue más moderado y crítico de la situación que se vivía.

La idea central de analizar la prensa escrita es la de pensarla no solo como fuente de información, sino también como problema, ya que "los posicionamientos y puntos de vista de la prensa deben ser analizados teniendo en cuenta su capacidad de influir en la toma de decisiones colectivas en tanto actores políticos"2. Así, se entiende al espacio editorial como aquel donde "se sistematiza explícitamente la posición institucional y la línea política ideológica de ese medio" 3 . Es definido como periodismo de opinión, donde se expone una problemática determinada, y se sugiere o reclaman medidas al respecto. Las temáticas que analiza el editorial son variadas, incluyendo desde temas de política internacional, hasta cuestiones locales.

Se analizarán también otros espacios de la superficie redaccional de los diarios, haciendo hincapié en las tapas y sus titulares, así como también en el espacio dedicado a determinadas noticias en uno u otro diario, intentando detectar presencias u omisiones.

\footnotetext{
${ }^{1}$ El Teatro de Operaciones del Atlántico Sur (TOAS) tuvo vigencia desde el 7 de abril al 14 de junio de 1982. Su jurisdicción abarcaba: Plataforma Continental, islas Malvinas, Georgias y Sandwich del Sur y el espacio aéreo y submarino correspondiente.

2 Borrelli, Marcelo. "El diario de Massera". Historia y política editorial de Convicción: la prensa del "Proceso". Bs. As., Koyatun Editorial, 2008. Pág. 15.

${ }^{3}$ Saborido, Jorge y Borrelli, Marcelo. Voces y silencios. La prensa argentina y la dictadura militar (1976 - 1983). Bs. As., Eudeba, 2011. Pág. 10.
} 


\section{María Laura Olivares}

\section{Los diarios Crónica y El Patagónico}

Ambos diarios comenzaron sus actividades en la década de 1960, momento en que la provincia de Chubut, creada por ley nacional en 1955, comenzaba a transitar sus primeros años de vida institucional, y la ciudad de Comodoro Rivadavia pasaba por una etapa de desarrollo conocida como el "boom petrolero" 4 , la que provocaba un gran aumento de la población.

Los diarios pioneros, El Rivadavia, fundado en 1915 y El Chubut en 1921, acompañaron el crecimiento de la ciudad desde los tiempos en que la misma formó parte del Territorio Nacional de Chubut, posteriormente cuando se constituyó como Gobernación Militar y en los inicios de la provincialización. Ambos dejaron de publicarse en 1965.

Al ritmo de los cambios que se vivían, el primer equipo de trabajo del diario Crónica consideró que era necesario un diario que reflejara los nuevos tiempos y diera lugar a los sectores más populares de la comunidad quienes, a su parecer, no se sentían identificados con los conservadores diarios pioneros. Por ello ubicaron los futuros talleres del diario en la parte alta de la ciudad, lugar que comenzaba a poblarse con migrantes oriundos del interior del país y países limítrofes. De esta manera, el primer número de Crónica vio la luz el 31 de enero de 1962, dirigido por su propietario, el Dr. Diego Zamit quien era abogado, miembro fundador de la Universidad Nacional de la Patagonia y Convencional Constituyente en 1957, por el Partido Demócrata Cristiano, para la redacción de la Constitución de la Provincia del Chubut ${ }^{5}$.

El Patagónico fue fundado por el escribano Roque González, gobernador de la provincia del Chubut entre octubre de 1963 y octubre de 1965, importante empresario de la zona, y al igual que el director de Crónica, Convencional Constituyente para la redacción de la Constitución de la provincia, representando a la Unión Cívica Radical del Pueblo. González, con el apoyo de otros empresarios de la ciudad, fundó la editorial "El Chenque", la que sería responsable de la publicación del diario, el cual estaba ubicado en el centro de la ciudad. El primer número de El Patagónico salió a la calle el día 30 de junio de 1967, expresando en su editorial:

Sabemos que los patagónicos quieren verse efectiva y patrióticamente integrados a la realidad nacional, no solo con las obligaciones -como acontece hoy- sino también en los derechos que como argentinos les corresponde, pero para que esta legítima aspiración sea posible es indispensable vencer las barreras del aislamiento (...) y

\footnotetext{
4 Se denomina "boom petrolero" al período comprendido entre 1958 y 1963, donde proliferaron los contratos petroleros entre Yacimientos Petrolíferos Fiscales (YPF) y empresas extranjeras, sobre todo norteamericanas, en el intento de reducir las importaciones de petróleo. Esto provocó la llegada de migrantes provenientes de otras provincias y de países limítrofes en busca de trabajo. El aumento de la población llevó al crecimiento de la ciudad, extendiéndose el ejido urbano, al tiempo que floreció la economía de la ciudad.

${ }^{5}$ Fuente: Armesto, Stella, Córdoba, Elvira y Figueroa, Raúl. Crónicas del Centenario. Comodoro Rivadavia 1901-2001. Bs.As., Compañía Gráfica Balbi, 2001.
} 
eliminar la ignorancia que sobre nosotros y nuestra región se tiene en otras latitudes de la patria6.

Hasta el momento no existen trabajos o análisis que den cuenta del posicionamiento histórico de estos diarios, ni sobre su vinculación con el poder o su grado de influencia en la sociedad. Sin embargo, de las trayectorias personales de sus directores puede considerarse que los propietarios de ambos diarios eran personas reconocidas en la sociedad comodorense. Tal vez uno de los elementos distintivos entre los diarios tenga que ver con la conformación e inicio del proyecto editorial. Mientras que El Patagónico parte de la iniciativa de un grupo de empresarios en ascenso de la ciudad y destacados profesionales, Crónica lo hace con un equipo de ex empleados del antiguo diario El Rivadavia al mando del Dr. Zamit.

Para 1982, Crónica y El Patagónico eran los únicos diarios que se publicaban en la ciudad.

\section{Los diarios comodorenses durante la guerra de Malvinas}

En abril de 1982, Comodoro Rivadavia7 formó parte del Teatro de Operaciones del Atlántico Sur, convirtiéndose en escenario continental de los aprestos bélicos para la guerra de Malvinas. La ciudad vio alterada su vida cotidiana durante la guerra. El movimiento de tropas, aviones, armas, insumos, entre otros, para ser enviados a las islas, fueron parte del paisaje de la ciudad durante la duración del conflicto, al igual que los simulacros de oscurecimiento y las alertas rojas sobre posibles bombardeos. De esta manera, los diarios reflejaron no solo las noticias nacionales vinculadas al conflicto bélico, sino también notas locales, es decir, acontecimientos relacionados a la guerra que tenían lugar en la ciudad.

Desde el inicio del gobierno militar, en el año 1976, regían estrictos controles sobre los medios de comunicación, como se refleja en el Comunicado $\mathrm{N}^{\circ} 19$ de la Junta Militar que establecía:

Será reprimido con reclusión de hasta 10 años el que por cualquier medio difundiere, divulgare o propagare noticias, comunicados o imágenes con el propósito de perturbar, perjudicar o desprestigiar la actividad de las fuerzas armadas, de seguridad o policiales ${ }^{8}$.

\footnotetext{
${ }^{6}$ Fuente: González, Roque. Comodoro 70’. Bahía Blanca, Editorial El Chenque SA, 1971. Pág. 158.

7 Comodoro Rivadavia era sede de la IX Brigada Aérea, del Regimiento de Infantería Mecanizado VIII "Gral. O’Higgings" y de la Compañía de Comunicaciones Mecanizada IX, dependientes de la Brigada Mecanizada IX "Cnel. Jorge Luis Fontana" con asiento en la ciudad.

8 Fuente: Varela, Mirta. "Entre la banalidad y la censura", publicado en www.camouflagecomics.com, consultado online el 20 de mayo de 2014.
} 


\section{María Laura Olivares}

Durante la guerra los estrictos controles se agudizaron. "Las Fuerzas Armadas argentinas no autorizaron corresponsales de guerra en Malvinas, como no fueran los oficiales, que a la vez tenían severas restricciones para visitar las primeras líneas de posiciones. Los británicos, en cambio, autorizaron a numerosos reporteros"9. Dada la imposibilidad de enviar corresponsales a las islas, Comodoro Rivadavia recibió a muchos periodistas nacionales e internacionales que llegaron para cubrir el desarrollo de la guerra.

Desde la ciudad, el 3 de abril de 1982, representantes de la prensa local y nacional pudieron viajar a las Malvinas solo por unas horas, para mostrar la recuperación de las islas. Uno de los periodistas locales recuerda su llegada a Puerto Argentino: “(...) Antes de aterrizar, nos 'recomendaron' que no tomáramos fotografías de algunos buques de guerra y de transporte que se hallaban fondeados en las bahías y ensenadas, ni tampoco de la estación aérea que estaba en plena etapa de militarización (...)”10.

A mediados del mes de abril, los periodistas locales, sumados a los periodistas nacionales que se encontraban en la ciudad, insistieron a los representantes de las Fuerzas Armadas para acceder a información sobre lo que acontecía en las islas. De esta manera, comenzaron a recibir noticias a través de un centro de informes teniendo como vocero al Cnel. Esteban Alberto Solís de la IX Brigada de Infantería, quien recordó en la primera rueda de prensa el artículo 222 del Código Penal: "Serán reprimidos con prisión o reclusión de 3 a 8 años el que revelare secretos políticos o militares concernientes a la seguridad, a los medios de defensa y a las relaciones exteriores de la nación" (Crónica, 10 de Mayo de 1982 pág. 3). Sobre este tema, un periodista local recuerda:

se armaba un 'tercer tiempo' periodístico, donde los de buena leche intercambiábamos versiones potables, descartábamos versiones de dudosa catadura u orientábamos a los de afuera para que al menos pudieran aportar 'notas color' a los afiebrados reclamos porteños de una guerra que nos quedaba muy lejos. ${ }^{11}$

Las autoridades militares controlaban la información que difundían las agencias noticiosas a nivel nacional, es decir que al llegar las noticias a los diarios, radios, etc., ya habían pasado el filtro de aquello que podía o no decirse. En este sentido, Crónica estaba vinculado a la Agencia Diarios y Noticias (DYN) y El Patagónico a la agencia Noticias Argentinas (NA).

La filtración de las noticias venía ya a nivel nacional (...) El gobierno apuraba para que se publicaran las versiones de Telam y Saporiti que eran las agencias oficiales (...) Habíamos conseguido en El Patagónico una clave de teletipo, poníamos una especie de número telefónico y lográbamos sintonizar directamente United Press

\footnotetext{
9 Lorenz, Federico. Malvinas. Una guerra argentina. Bs. As., Sudamericana, 2009. Págs. 54 y 55.

${ }^{10}$ Periodista Carlos Acosta. Fuente: Suplemento diario El Patagónico, 02 de abril de 2012.

${ }^{11}$ Nota del Periodista Daniel Alonso (quien trabajaba en el diario El Patagónico durante la guerra). Fuente: Suplemento diario El Patagónico, 02 de abril de 2012.
} 
International y Associated Press donde veíamos la versión del enemigo que no podíamos publicar ${ }^{12}$.

En este marco, el control sobre los medios de comunicación a nivel nacional llevó a que el día 05 de junio de 1982, por orden del Tte. Gral. Leopoldo Galtieri se clausure El Patagónico y la Agencia de Noticias Argentinas (NA) por "haber violado la pauta referida a difusión de la información sobre el desarrollo de las operaciones militares en el Atlántico Sur" (Crónica, 05 de junio de 1982, pág. 2). Sobre el tema, el propietario del El Patagónico manifestó en las páginas de Crónica que no había sido notificado de la sanción, aunque sí dijo hablar con colegas de la agencia de noticias, quienes se sorprendieron por la sanción dado que las noticias referidas al "puente aéreo" habían sido publicadas por distintos periódicos del país. Como respuesta a la clausura, El Patagónico publicó una nota muy pequeña, en la sección de noticias sobre Malvinas, titulada "Como decíamos ayer" (El Patagónico, 07 de Junio de 2014, pág. 3) donde expresa que, al parecer, los motivos de la clausura se debieron a haber reproducido, la semana anterior, un cable emitido por la agencia NA, que también había sido publicado por otros medios de prensa, pero solo fueron sancionados la agencia de noticias y El Patagónico. La sanción fue revisada y levantada 13 .

De esta manera, los medios de comunicación debieron actuar en un marco de censura aún más grande que el que regía desde 1976, ya que para las Fuerzas Armadas el control de la información era vital por cuestiones de estrategia de guerra.

\section{Análisis de los espacios editoriales}

Dados los límites impuestos por el gobierno militar al manejo de la información, es importante analizar cómo se comportaron los diarios locales en ese marco, comenzando por lo expresado en los editoriales, espacio desde el que se expresa la postura política de un medio.

El espacio editorial del diario Crónica se ubicaba en la página 12, del lado izquierdo, a dos columnas, y se anunciaba allí como espacio editorial con el nombre del diario, el año de vida y el número de ejemplar. Se agregaba también el nombre de su director, luego el título del editorial y el texto. El editorial de El Patagónico se ubicaba por lo general en la página 9, también recuadrado y a dos columnas, teniendo como encabezado el logo del diario y datos sobre su fundación,

\footnotetext{
12 Entrevista personal al periodista Daniel Alonso, 24 de febrero de 2013.

${ }^{13}$ La nota por la que se sanciona a El Patagónico y a la agencia "Noticias Argentinas" se refería a la posibilidad que aeronaves inglesas, denominadas Vulcan, estuvieran apostadas en las costas brasileras.
} 


\section{María Laura Olivares}

número de edición, el nombre de su director, y la fecha del editorial, el título y el texto ${ }^{14}$.

En líneas generales casi la totalidad de los editoriales de Crónica del mes de abril se refieren al tema Malvinas, mientras que la mayor parte de los editoriales del mismo mes de El Patagónico no lo abordan como tema central, o sólo hacen una pequeña referencia, dedicándose más que nada a reflexionar sobre otros temas, como la importancia de la minería, el turismo, entre otros.

Los editoriales del mes de mayo, en ambos diarios, se refieren en su totalidad a temas vinculados con la guerra, quizá por el hecho de haberse iniciado los enfrentamientos armados el 1 de mayo.

Los editoriales del mes de junio de El Patagónico comienzan los primeros días a reflexionar de a poco sobre la Argentina de posguerra. A mediados de mes se habla de los problemas de comunicaciones, de los problemas de la enseñanza y recién después del día 20 algunos de sus editoriales analizan el tema de la paz. En cambio, el diario Crónica en el mes de junio se refiere a la guerra en sus editoriales analizando el esfuerzo de la ciudad, el rol de Chile, la visita del Papa, entre otros, y después del día 20 aproximadamente, comienza a hablar de la derrota y de la información sobre prisioneros de guerra.

En líneas generales, se puede considerar que Crónica dedicó mucho más el espacio editorial al tema Malvinas y sus distintas variantes, mientras que El Patagónico reflexionó sobre otras cuestiones que no tenían relación con el conflicto en las islas.

Analizar en profundidad algunos de los editoriales, ayudará a comprender mejor el posicionamiento de cada diario ante la guerra, estableciendo similitudes y diferencias.

Los primeros días de abril los editoriales de ambos diarios comienzan a hacer referencia directa o indirecta al tema Malvinas. El Patagónico del domingo 4 de abril, hace referencia indirecta al tema (llamándolo el momento histórico que vive el país) en su editorial titulado "Un riesgo que hay que correr". Allí su director, habla de la posibilidad de expresarse libremente:

Ser ciudadano independiente implica, las más de las veces, estar tentado de callarse la boca para no ser juzgado por los incompetentes o asumir un cierto heroísmo para afrontar los malentendidos (...) El momento histórico que está viviendo el país, debe servir sin duda para poder asumir un riesgo permanente en las opiniones, de lo que conviene o no conviene, y debe servir además para la unión de todos los argentinos (El Patagónico, 4 de abril de 1982, pág. 9).

Quizá su director estaba tomando posición ante la censura que imperaba.

\footnotetext{
${ }^{14}$ Durante el período en estudio los editoriales fueron variando en algunas oportunidades la página de aparición, ubicándose algunas veces en páginas anteriores o posteriores, o directamente sin aparecer durante algunos días.
} 


\section{Entre el triunfalismo y la moderación}

El diario Crónica del 6 de abril publica su editorial referido a Malvinas, titulándolo "Unión y serenidad son consignas de la hora". Allí se exalta la madurez y el patriotismo puesto de manifiesto en todo el país, donde considera que:

En forma espontánea, sin declinar las respectivas posiciones asumidas a través del tiempo en lo que a los problemas y temas internos se refiere, los distintos sectores que componen la comunidad nacional, se han manifestado solidarios con la actitud del gobierno (...) Lo ocurrido en los últimos días no debe ser tomado a la ligera con la mentalidad de un triunfo deportivo circunstancial, porque se trata de algo mucho más trascendente (...) Todos los actos que protagonicen los argentinos deben estar signados por la unidad total y por un elevado sentido de la responsabilidad (Crónica, 6 de abril de 1982, pág. 8).

En la nota, se enfatiza que las virtudes "castrenses" y cualidades humanas puestas de manifiesto en Malvinas, deben caracterizar a todo el pueblo argentino y propone "diferir hasta más adelante la discusión de los grandes y graves problemas que en otros órdenes tiene la comunidad nacional, sin que ello signifique olvidarlos o minimizarlos" (Crónica, 6 de abril de 1982, pág. 8).

En referencia a los problemas internos del país, El Patagónico recién a mediados del mes de mayo se refiere al tema considerando que:

Las Malvinas están por encima de cualquier otro problema que estemos atravesando como país, incluso el económico (...) Somos muchos -ha dicho Sábato- los que durante este gobierno hemos denunciado el desmantelamiento de nuestro patrimonio económico y seguiremos haciéndolo cada vez que sea necesario, pero el problema de las Malvinas está por encima de cualquier discrepancia de política interior, es algo que todos los argentinos han sentido entrañablemente desde que Inglaterra usurpó las islas por la fuerza; su recuperación es un sueño que desde entonces han soñado todos los hombres y mujeres de nuestra tierra (...) Esto no es una lucha de una democracia contra una dictadura militar, como ha dicho un ministro inglés, es la lucha de un imperio contra un pueblo entero (El Patagónico, 15 de mayo de 1982, Pág. 9).

Uno de los temas recurrentes que aparecieron en los editoriales de ambos diarios se refería al apoyo de ciertos países a la Argentina ante el conflicto. Sobre este tema ambos periódicos parecen coincidir en sus posturas. Por ejemplo, en el editorial del 09 de abril de Crónica, titulado “¿Cuáles son nuestros verdaderos amigos?" se analizan las votaciones en el Consejo de Seguridad de la Organización de las Naciones Unidas (ONU), tras la presentación que Gran Bretaña hiciera en ese organismo luego del desembarco argentino en Malvinas. Se analizan cuáles fueron los votos en contra para Argentina, como los de Estados Unidos, y las abstenciones de Rusia y China. Se critica la posición de España, quien a pesar de tener problemas con Gran Bretaña por Gibraltar se abstuvo de votar, según el director de Crónica, "porque está ansiosa de ingresar a la OTAN (Organización del Tratado del Atlántico Norte) y a la Comunidad Económica Europea". Considera que cada cual se 


\section{María Laura Olivares}

pronunció en esa votación a favor de sus intereses particulares y que esto debe hacernos reflexionar sobre quiénes son nuestros verdaderos amigos. (Crónica, 09 de abril de 1982, pág. 12).

Sobre el apoyo o no de algunos países a la Argentina, El Patagónico publica un editorial a inicios del mes de mayo titulado "Una nueva forma de aprender la Historia" en el cual critica a Inglaterra y considera que el motivo por el cual algunos países americanos no apoyan a la Argentina es culpa de los gobiernos (que son ocasionales) y no de los pueblos. (El Patagónico, 5 de mayo de 1982, pág. 9).

Otro de los temas en los cuales parecen coincidir los periódicos es en la manera de ver a Gran Bretaña. El Patagónico titulaba su editorial del 1 de mayo: "El triunfo sobre la prepotencia", donde consideraba que "Inglaterra que se proclama campeón de la democracia en el mundo moderno, tiene todavía ciudadanos de primera y de segunda clase. Los malvineros pertenecen a ésta última" ( $E l$ Patagónico, 01 de mayo de 1982, pág. 9). Días posteriores tratará a los ingleses de criminales de guerra: “¿Cuál será el juicio de la historia para los ingleses de este tiempo, ametrallando a náufragos en una balsa en medio del Atlántico, en las frías aguas del sur?" (El Patagónico, 13 de mayo de 1982, pág. 9).

El editorial de Crónica del 9 de mayo se titula "La actitud británica", donde analiza el hundimiento del Belgrano y donde su director considera:

El fascismo no murió en 1945 luego de la derrota alemana y japonesa. Está vigente y se manifiesta vital y lozano, con distinto ropaje, es cierto, desde el número 10 de la calle Downing de Londres y desde la Casa Blanca y el Pentágono de Washington. (Crónica, 9 de mayo de 1982, pág. 6).

También coincidían en algunas apreciaciones sobre la economía de guerra. Crónica manifestaba que en una virtual economía de guerra, en Comodoro Rivadavia se comenzaban a notar algunos efectos económicos, donde el comercio pasaba por una especie de bonanza que, "aunque no se ha llegado a producir un estado de acaparamiento de artículos de primera necesidad, sobre todo en el terreno de la alimentación, resulta evidente que las compras de mucha gente en ese campo superan los niveles acostumbrados, aún más quizá que en época de normalidad económica" por ello habían disminuido las ventas del comercio no dedicado a la alimentación, lo que perjudicó a algunos empresarios que no pudieron cumplir con determinados pagos y compromisos comerciales, teniendo que enfrentarse a problemas legales. En este contexto, desde el editorial se solicita que se dicten "algunas normas de carácter transitorio para determinados tipos de actividades comerciales, industriales y productivas (...) que sirvan para superar esta lamentable coyuntura” (Crónica, 15 de abril de 1982, pág. 12). El Patagónico por su parte consideraba que se estaba cerca de una economía de guerra y que "la especulación debe tomarse como un acto de subversión y no de mera omisión de obligaciones, así como la ocultación de mercaderías y elementos que necesita la población" (El Patagónico, 20 de abril de 1982, pág. 10). De la misma manera los 
primeros días de mayo critica a aquellos que especulan con los precios y a los aumentos inexplicables de algunos productos. Pero critica también a los que sacan su plata del banco o acopian determinados productos (El Patagónico, 4 de mayo de 1982, pág. 9).

Ambos diarios parecen coincidir además, en la conflictiva relación entre la primer ministro Margaret Thatcher y parte de la prensa inglesa. En este sentido El Patagónico considera, utilizando el ejemplo histórico de las invasiones inglesas, que se engaña a los ingleses ocultándole las derrotas:

En la hora de la verdad se habrán convencido de la valentía y espíritu militar de nuestras Fuerzas Armadas, que la golpean con firmeza. En fin, las Malvinas ya están recuperadas para siempre de las garras del ya 'reumático león', pero las futuras generaciones inglesas ¿llegarán a saberlo? (El Patagónico, 10 de mayo de 1982, pág. 10).

Crónica del 15 de mayo se refiere a "La señora Thatcher y la prensa inglesa", donde expresa "Nada se sabe, a través de los diarios y la televisión inglesa, del número exacto de aviones 'Sea harrier' y helicópteros 'Sea King' derribados en las distintas acciones militares ocurridas en Malvinas, como tampoco sobre el número de víctimas inglesas en las mismas". Considera obvio el descontento de Thatcher con la prensa británica e insiste en que este enojo puede deberse a que en algún momento esos medios dieron a "conocer alguna información diplomática o militar que se ajusta a la verdad" (Crónica, 15 de mayo de 1982, pág. 12).

Pero así como se pueden encontrar coincidencias entre las opiniones editoriales de ambos diarios, también hay claras diferencias.

Crónica apela recurrentemente desde los editoriales al rol de la población de la ciudad como solidaria, comprometida, al tiempo que resalta la idea de "normalidad" y las bondades de la Junta de Defensa Civil15. "La gran unión del pueblo argentino", "Solidaria actitud en la emergencia", son algunos de sus títulos. A mediados de abril, el diario resalta la solidaridad y sentido comunitario de la población, juntando aportes destinados a los soldados, y sobre todo de las mujeres, que se hicieron presentes en los cursos de primeros auxilios y en otros sectores vinculados a la tarea asistencial, considerando que:

(...) la vida ha seguido y sigue normalmente en Comodoro Rivadavia (...) Cada uno en el cumplimiento de sus tareas y obligaciones, en el desempeño de las actividades

\footnotetext{
15 Una de las primeras medidas tomadas por la ciudad de Comodoro Rivadavia al conocerse la noticia del 02 de abril fue convocar a la Junta de Defensa Civil. La misma había sido creada por Decreto Nacional Ley № 6250/58, para la Defensa Antiaérea Pasiva Territorial, convocando a todos los habitantes sin distinción de sexo, edad o nacionalidad, a ser responsables de la defensa antiaérea, considerando estos deberes como carga pública irrenunciable. Este decreto fue puesto en práctica en 1978, donde se lo recupera frente al inminente conflicto con Chile por el Canal de Beagle, momento en el que en Comodoro Rivadavia se ensayaron simulacros de oscurecimiento y evacuación, como medidas preventivas ante un posible conflicto armado. Luego de 1978 la Junta de Defensa Civil es disuelta y vuelta a convocar en 1982.
} 


\title{
María Laura Olivares
}

comerciales y productivas, en la administración pública o la docencia, en la prestación de servicios o desempeño de las tareas personales, los niños y jóvenes en el aula y las mujeres abocadas a los menesteres hogareños y a la atención de sus esposos e hijos, todos están haciendo gala de una serenidad y responsabilidad dignas de ser remarcadas (Crónica, 14 de abril de 1982, pág. 12).

En otras ocasiones analiza los ejercicios de oscurecimiento ${ }^{16}$ que se llevan adelante en la ciudad organizados por Defensa Civil y sobre algunos casos de negligencia que no cumplieron con la normativa de oscurecer la ciudad. En este sentido, y sobre estos casos, considera que:

\begin{abstract}
'la letra con sangre entra', la autoridad que corresponda debería establecer y dar a conocer mediante la mayor publicidad posible, la adopción de severas normas punitivas, fundamentalmente de carácter económico, para quienes no observen escrupulosamente las medidas de seguridad tan reiteradamente difundidas a través de todos los medios de comunicación social (...) (Crónica, 16 de abril de 1982, pág. 12).
\end{abstract}

El sábado 1 de mayo, el editorial se titula "Una ciudad que sigue con su vida normal", donde su director manifestaba que en la ciudad las actividades cotidianas se cumplían con total normalidad, las escuelas funcionaban normalmente al igual que el comercio, restaurantes, cines y lugares de esparcimiento. Sobre estos últimos señala que incluso habrían aumentado su actividad dada la gran cantidad de periodistas que arribaron a la ciudad. La nota finalizaba de esta manera: "una comunidad normal en todo sentido, preocupada, quizá tensa, pero cumpliendo con sus obligaciones normales y las nuevas que la presente hora nos está exigiendo a todos" (Crónica, 1 de mayo de 1982, pág. 6).

Desde los editoriales de El Patagónico no se apela a la idea de vida cotidiana inalterada como en Crónica. Sí, en distintas ocasiones, se resalta el rol de la población como solidaria, pero éste nunca es el eje central del editorial. El 21 de abril considera que "la sociedad comodorense deja todo de lado cuando se trata de estar al lado de la patria sin ese falso nacionalismo a ultranza sino nutrido de las fuentes que nos dieron este hermoso país que vivimos". Al mismo tiempo resalta, "esta realidad, no debe ser desvirtuada con actitudes oficiales que minimicen la situación”. (El Patagónico, 21 de Abril de 1982, pág. 10).

Sobre lo manifestado en Crónica, que la ciudad seguía con su vida normal a pesar de la guerra, se ha sostenido que:

(...) el gobierno militar se esforzó desde sus comunicaciones oficiales y desde la influencia ejercida en los medios de comunicación, por alentar la idea de normalidad

\footnotetext{
${ }^{16}$ Los ejercicios de oscurecimiento consistían en suprimir por completo toda luz visible en la ciudad con el fin de evitar que la iluminación artificial facilite la orientación, localización e identificación de los objetivos, en caso de ataque aéreo nocturno.
} 


\section{Entre el triunfalismo y la moderación}

y de vida cotidiana inalteradas (...) El control y la violencia fueron situaciones extraordinarias que sin embargo fueron rutinizadas y vividas como cotidianas a partir del esfuerzo de disciplinamiento social que caracterizó a la última dictadura militar argentina ${ }^{17}$.

En síntesis, mientras que Crónica dedica casi la totalidad de sus editoriales al tema Malvinas o temas vinculados al conflicto, El Patagónico presenta variantes, tratando algunas veces el tema indirectamente, o no tratándolo. En algunos temas centrales presentan posiciones similares, como la visión sobre Gran Bretaña. Por otra parte, se exalta desde las páginas de Crónica la idea de normalidad de la situación, de tranquilidad de la población, mientras que El Patagónico rescata el rol de la población en muy pocas ocasiones y no apela en ningún momento a la idea de normalidad.

Por lo expuesto, el análisis de los espacios editoriales no permite catalogar a un diario como triunfalista y a otro como moderado, que es lo que se busca comprobar en este trabajo, ya que los temas analizados desde la tribuna que puede ser el editorial, no muestran estas posiciones. Pero dicho análisis resulta fundamental para reconocer rasgos distintivos en cuanto al tratamiento de los temas de interés a comunicar, la forma en que se comunican esos temas y la postura frente al conflicto que muestra los intereses de cada diario. En este sentido, mientras que Crónica destaca el rol de la población y su comportamiento ante la guerra, dando protagonismo a la población desde el editorial, El Patagónico utiliza el espacio para reflexionar sobre otros temas vinculados al turismo, la minería y para pensar en la Argentina de posguerra, quizá poniendo de manifiesto en estas actitudes el contrato establecido desde sus inicios con sus lectores.

\section{Análisis de la superficie redaccional}

¿Qué ocurre con los titulares, notas centrales y noticias locales durante la guerra?.

Crónica presentaba en el periodo en estudio, su tapa con dos o tres titulares de tamaño mediano. Si la noticia era muy destacada apelaba al gran tamaño de las letras, ocupando media página o más. Acompañaba con fotos los titulares. En las primeras páginas aparecían noticias locales o provinciales de importancia, luego el editorial y las noticias internacionales, que durante la guerra tuvo a ese tema como principal protagonista, utilizando titulares que abarcaban dos páginas cuando la información era muy importante. Luego se ubicaban los datos del cine, el tránsito aéreo, un crucigrama, el horóscopo, historietas y teléfonos útiles. A esto le seguía la

\footnotetext{
17 Martinez, Julieta y Olivares, María Laura: "Vida cotidiana y participación ciudadana: la sociedad comodorense durante la Guerra de Malvinas". Revista Textos y Contextos desde el sur, № 1, Vol I (1), diciembre 2013, disponible en http://www. revistas.unp.edu.ar/index.php/textosycontextos. Pág. 55.
} 


\section{María Laura Olivares}

información deportiva y en la contratapa se ubicaban algunas noticias internacionales o locales dependiendo del día. Por lo general, los clasificados aparecían en el medio de la sección de deportes.

El Patagónico utilizaba titulares más pequeños y variados en su tapa y apelaba mucho al fondo negro con letras blancas para dar importancia (y no tanto al tamaño). A continuación, comenzaban las páginas de noticias internacionales, o, durante el conflicto, sobre la guerra, cubriendo a veces 4 páginas con información. A continuación se ubicaban las noticias locales, o de ciudades cercanas. En la página 9 se ubicaba por lo general el editorial y luego el crucigrama, teléfonos útiles, cartelera del cine y las historietas. Seguidamente aparecían notas de la provincia en general y la sección de sociales. Luego se ubicaban los clasificados y las noticias deportivas. La contratapa se ocupaba de notas internacionales mezcladas con locales.

El 2 de abril de 1982 ambos diarios reflejaron el desembarco argentino en Malvinas. Crónica titulaba en su primera edición, “iAlerta Roja! Peligra la paz en las islas del sur. Posibilidad de un desembarco argentino en las islas Malvinas". Al tiempo que El Patagónico publicaba “Día 'D' para las Malvinas. Hoy con las primeras luces del día serán recuperadas". Horas más tarde ambos diarios debieron lanzar una segunda edición, donde Crónica titulaba "Recuperamos las Malvinas. Embandere su edificio. La celeste y blanca flamea en el archipiélago". El 3 de abril el diario presentaba una portada especial titulada "Crónica de una jornada gloriosa", jugando con el nombre el diario, con fotos de la bandera argentina, de Galtieri y de la gente que se volcó en las calles a celebrar la recuperación.

Sobre los titulares de primera plana Crónica variaba mucho el tamaño de letra utilizado, resaltando la importancia de esa noticia. Por ejemplo el 26 de abril publica en un titular muy grande "Guerra en las Georgias". Del mismo tamaño y dando énfasis al título, el 2 de mayo publica "Grandes pérdidas inglesas", ocupando más de media página, casualmente el mismo día en que es hundido el Crucero ARA Gral. Belgrano en la zona de exclusión. Sobre este último el diario hace referencia recién el día 04 de mayo titulando "Dramático salvataje en alta mar".

A partir del 5 de mayo comienza a aparecer en la primera plana de Crónica un cartel con la inscripción “¡Vamos Argentina todavía!” el cual se mantendrá, con un pequeño intervalo, hasta la finalización de la guerra. A esta frase le seguía un gran titular: "Dos sea harrier y el destructor inglés Sheffield abatidos por el fuego argentino", el cual ocupa media página. Al día siguiente el encabezado se amplía con la frase: “Hasta la victoria final ¡Vamos argentina todavía!”, el cual va creciendo en tamaño con el pasar de los días.

Desde el 8 de mayo comienza a aparecer en la página 5 la propaganda "Ya estamos ganando. Argentinos a vencer", la cual ocupaba una gran parte de la hoja y era la pauta publicitaria enviada por el gobierno militar. A partir de este día las publicidades oficiales se hacen casi diarias apareciendo a página entera. 


\section{Entre el triunfalismo y la moderación}

El 14 de mayo desaparece por unos días de la primera plana del diario “¡Vamos Argentina todavía!”, pero en su interior continúa la propaganda oficial a página entera, como la reconocida "Ganemos la batalla en todos los frentes".

El 22 de mayo reaparece el cartel de "Hasta la victoria final ¡Vamos Argentina todavía!" pero en un tamaño mucho menor, siendo el titular: "Duro revés para los piratas". A partir de este día la propaganda oficial va disminuyendo su tamaño.

El 26 de mayo el titular anuncia "Seguimos bajando aviones y barcos", al tiempo que en el interior del diario una de las notas considera "Con espontáneo júbilo fue recibido el presidente Galtieri". Otros titulares de fin de este mes rezaban: "El temple argentino es lo que mata", "La fuerza inglesa no pudo con la garra criolla".

Los primeros diez días de junio los titulares seguían la lógica de fines de mayo: "Inglaterra ha sufrido la mayor derrota del siglo", "Ingleses Acorralados!", "Infligimos otra dura derrota a los ingleses", "Los ingleses retroceden. Le tienen pánico a la artillería argentina”. El 14 de junio, día de la rendición, el titular de tapa sostenía "Fue creada una 'zona de seguridad' en las Malvinas" resaltando, en el interior del diario, la escasa actividad bélica de los invasores.

En cuanto a las noticias que aparecen en las páginas interiores, las nacionales reproducen los comunicados numerados difundidos por el gobierno militar; notas de opinión sobre la guerra tomadas de la Agencia DYN, pero también de las oficiales Telam y Saporiti. En cuanto a las notas del ámbito local, Crónica dedica mucho espacio a las recomendaciones de la Junta de Defensa Civil, sobre todo las dirigidas a las amas de casa, a las actividades solidarias de la comunidad, como el tejido de bufandas y guantes, entre otras actividades. Por ejemplo, una nota del 01 de mayo instaba a las amas de casa a colaborar con la Junta de Defensa Civil. Su Director solicitaba:

(...)Las amas de casa (...) en los momentos que vive el país, deben seguir con su comportamiento habitual, el de todos los días, de todos los años, este, no debe diferir en nada. (...) Las madres deben actuar con total tranquilidad, porque en la medida que ellas la tengan, se la podrán transmitir a sus hijos. Es importante evitar el pánico, el miedo descontrolado al apoderarse del individuo no le permite razonar, embruteciéndolo, y anulándolo completamente" (Crónica, 1 de mayo de 1982 pág. 11).

Por su parte, El Patagónico presenta como una de sus características que no utiliza por lo general un único titular más grande e importante, sino varias noticias en primera plana con igual espacio y letra. Por ejemplo, el 04 de abril titula "Solo sin vida nos sacarán. Los ingleses se van. Los argentinos quieren ir", y días más tarde "Si se concreta el bloqueo acudiremos a las armas".

El 28 de abril la tapa de El Patagónico anunciaba: "Inminente ataque inglés a las Malvinas", "Periodistas extranjeros tienen 48 horas para abandonar la zona de acuerdo a órdenes del V Cuerpo del Ejército. Deben estar en Bs. As. y no en la zona de operaciones para evitar difundir noticias de carácter operacional". 


\section{María Laura Olivares}

Durante los primeros días del mes de mayo titula "Rechazaron la invasión y hay una tensa calma. El portaviones Hermes estaría seriamente dañado", intentando no hacer afirmaciones tan triunfalistas ni contundentes.

El día 4 de mayo El Patagónico hace referencia al hundimiento del Crucero ARA Gral. Belgrano, titulando "Alevoso acto de agresión”. Mientras que al día siguiente publica: "Duro golpe sufrió la flota británica".

Al igual que en Crónica, el 8 de mayo en la página 15 aparece por primera vez la propaganda "Argentinos a vencer" a página entera, con los pulgares en alto. Durante los días siguientes algunos de los titulares son: "Inhumano ataque a pesquero argentino", seguido de una foto de la agencia Télam de un avión inglés abatido; "Dos fragatas inglesas seriamente averiadas"; "Aguardan un ataque masivo a las islas"; "Los invasores están cercados"; "Rechazase un ataque inglés sobre Darwin".

Los primeros días del mes de junio se habla de logros de las tropas argentinas: "Nuestra artillería hostigó duramente posiciones inglesas"; "Tropas argentinas repelieron fuerzas de avanzada inglesas"; "La aviación devastó intento de desembarco". Los días 11 y 12 de junio las noticias muestran la llegada del Papa Juan Pablo II a la Argentina.

Los titulares del 14 de junio no hablan de rendición de las tropas argentinas. Al día siguiente la primera plana titulaba "Un cese al fuego no concertado rige en las Malvinas". Los días posteriores no se hace alusión al fin de la guerra ni a la rendición. Recién el 24 de junio El Patagónico titula "Tras la derrota militar, la crisis ha tocado fondo".

En cuanto a las noticias que aparecen en las páginas interiores, al igual que el diario Crónica las nacionales reproducen los comunicados numerados emanados del gobierno militar, notas de opinión sobre la guerra tomadas de la Agencia NA, incluyendo algunas de Télam y Saporiti. En cuanto a las notas vinculadas al ámbito local, a diferencia de Crónica no se les da tanto espacio al accionar de la población ni a las recomendaciones de Defensa Civil, llegando incluso a criticar al organismo por su accionar, considerando que si bien insta a mantener la calma, los mensajes que difunde son "lo más injustificadamente alarmistas que podían ser, estando mal redactados los comunicados (...). Esas misteriosas como alarmistas convocatorias, inflamaron la imaginación popular, y al rato ya los heridos y muertos que llegaban de Malvinas se contaban por cientos". (El Patagónico, 03 de mayo de 1982, pág. 6).

“Cómo podía ser que se perdiera una guerra que según las informaciones oficiales se venía librando con buenos resultados, a pesar del avance británico?"18.

Como lo demuestra el análisis de los titulares utilizados por los diarios y algunas noticias en las que hicieron hincapié, el diario Crónica fue desde sus titulares asumiendo una posición triunfalista, como la que sostenía el gobierno

${ }^{18}$ Lorenz, Federico. Malvinas. Una guerra argentina. Bs. As., Sudamericana, 2009. Pág. 167. 


\title{
Entre el triunfalismo y la moderación
}

militar y difundían algunos medios de tirada nacional como la revista "Gente"19 reflejando exageradamente las acciones argentinas en Malvinas, mientras que el diario El Patagónico, que también reproducía las únicas noticias que llegaban, ya mediadas por el gobierno, se mostraba más cauto o moderado en sus titulares. Como considera Federico Lorenz:

\begin{abstract}
Por encima de los escuetos comunicados del Estado Mayor Conjunto, diferentes medios gráficos bombardearon a sus lectores con mensajes e informaciones teñidas de un tono triunfalista, peyorativo hacia el adversario y que exaltaba las virtudes argentinas, encarnadas en jóvenes soldados que serían enviados a Malvinas, o que ya estaban allí. Este panorama era mucho más monolítico en los grandes centros urbanos, por un lado alejados del escenario del conflicto, y por el otro donde el consumo de medios gráficos era mucho mayor. 20
\end{abstract}

En este contexto, no es posible afirmar si el triunfalismo de Crónica se debía a una estrategia comunicativa para destacar un tema utilizada regularmente por el diario cuando entendía que un tema ameritaba un tratamiento destacado, o a cierta complicidad con el gobierno militar, ya que no existen otros estudios sobre el tema. Sí es posible considerar que, aún en el marco de censura, el triunfalismo no era una imposición del gobierno militar, ya que el mismo no es visible en la superficie redaccional de El Patagónico el cual se encontraba bajo las mismas normas que Crónica. En este sentido, es más factible vincular este posicionamiento con una estrategia del diario para llegar a una mayor cantidad de lectores.

\section{Conclusión}

Este trabajo analizó las posturas tomadas por los diarios de la ciudad de Comodoro Rivadavia durante la guerra de Malvinas, buscando demostrar que, en el marco de la censura, el diario Crónica acompañó las versiones oficiales y difundió el espíritu triunfalista del gobierno militar, mientras que el diario El Patagónico fue más moderado y crítico de la situación que se vivía.

En este sentido, el análisis de los editoriales de ambos diarios durante los meses de abril, mayo y junio de 1982 no permite ser concluyente respecto de si adhieren o no a posiciones triunfalistas o moderadas. Pero dicho análisis resulta fundamental para reconocer rasgos distintivos en cuanto al tratamiento de los temas de interés a comunicar, la forma en que se comunican esos temas y la postura frente al conflicto que muestra los intereses de cada diario. En este sentido, mientras que Crónica destaca el rol de la población y su comportamiento ante la guerra, dando protagonismo a la población desde el editorial, El Patagónico

\footnotetext{
19 Gago, María Paula y Saborido, Jorge. "Somos y Gente frente a la guerra de Malvinas: dos miradas en una misma editorial”, en Saborido, Jorge y Borrelli, Marcelo. Voces y silencios. La prensa argentina y la dictadura militar (1976 - 1983). Bs. As., Eudeba, 2011.

20 Lorenz, Federico. Malvinas. Una guerra argentina. Bs. As., Sudamericana, 2009. Pág. 55.
} 


\section{María Laura Olivares}

utiliza el espacio para reflexionar sobre otros temas vinculados al turismo, la minería y para pensar en la Argentina de posguerra, quizá poniendo de manifiesto en estas actitudes el contrato establecido desde sus inicios con sus lectores. Si se tiene en cuenta lo manifestado por los diarios desde su fundación, puede entenderse que Crónica, que desde sus inicios pensaba en llegar a los sectores populares y darles voz, resalte en todo momento el rol de la población como solidaria, protagónica, unida, al mismo tiempo que resalta el rol de la ciudad y su esfuerzo en tiempos de guerra. El Patagónico por otro lado, no establece ese contrato con los lectores, expresando en sus editoriales una visión más despegada de lo cotidiano, donde la agenda de temas que recupera para el análisis tiene que ver con posicionamientos sobre lo económico, lo político y el futuro.

El análisis de los titulares y otros espacios de la superficie redaccional de ambos diarios, sí permite comprobar la hipótesis de trabajo. Crónica refleja un triunfalismo absoluto, materializado en titulares como "Inglaterra ha sufrido la mayor derrota del siglo"; entre otros, mientras que el tratamiento de las noticias locales refleja el statu quo propuesto por el gobierno, apelando a la idea de normalidad y vida cotidiana inalteradas. Los titulares de El Patagónico, en cambio, se muestran más moderados: "El portaviones Hermes estaría seriamente dañado".

Como antes se mencionó, no es posible afirmar si el triunfalismo de Crónica se debía a una estrategia comunicativa para destacar un tema, utilizada regularmente por el diario, o a cierta complicidad con el gobierno militar, ya que no existen otros estudios sobre el tema. Sí es posible considerar que evidentemente, aún en el marco de censura, el triunfalismo no era una imposición del gobierno, ya que, como antes se mencionó, el mismo no es visible en la superficie redaccional de El Patagónico. En este sentido, se acuerda con Federico Lorenz quien considera que "en muchas ocasiones, el triunfalismo argentino se debió más a la propia iniciativa de algunos medios que a una orden de la Junta Militar"21, explicando de alguna manera, el triunfalismo de Crónica y la moderación de El Patagónico.

Este análisis se presenta como una primera mirada para comenzar a investigar el rol de los medios locales como actores políticos en el marco general del contexto dictatorial, campo aún inexplorado, dejando interrogantes que aún no es factible responder como los posibles vínculos de miembros de estos diarios con las autoridades militares, de la influencia o no de las pertenencias políticas de los directores en sus discursos, si primaba una lógica empresarial de aumentar las ventas y desde allí las diferentes estrategias de transmisión de las noticias, o del porqué de apelar a la idea de normalidad de la situación a pesar de la guerra, entre otros.

${ }^{21}$ Lorenz, Federico. Malvinas. Una guerra argentina. Bs. As., Sudamericana, 2009. Pág. 54. 


\section{Entre el triunfalismo y la moderación}

\section{Bibliografía:}

Armesto, Stella, Córdoba, Elvira y Figueroa, Raúl. Crónicas del Centenario. Comodoro Rivadavia 1901-2001.Bs.As., Compañía Gráfica Balbi, 2001.

Borrelli, Marcelo. "El diario de Massera". Historia y política editorial de Convicción: la prensa del "Proceso". Bs. As., Koyatun Editorial, 2008.

Gago, María Paula y Saborido, Jorge. "Somos y Gente frente a la guerra de Malvinas: dos miradas en una misma editorial", en Saborido, Jorge y Borrelli, Marcelo. Voces y silencios. La prensa argentina y la dictadura militar (1976 - 1983). Bs. As., Eudeba, 2011.

González, Roque. Comodoro 70’. Bahía Blanca, Editorial El Chenque SA, 1971.

Lorenz, Federico. Malvinas. Una guerra argentina. Bs. As., Sudamericana, 2009.

Martinez, Julieta y Olivares, María Laura: "Vida cotidiana y participación ciudadana: la sociedad comodorense durante la Guerra de Malvinas". Revista Textos y Contextos desde el sur, $\mathrm{N}^{\circ}$ 1, Vol I (1), diciembre 2013, disponible en http://www. revistas.unp.edu.ar/index.php/textosycontextos.

Saborido, Jorge y Borrelli, Marcelo. Voces y silencios. La prensa argentina y la dictadura militar (1976 - 1983). Bs. As., Eudeba, 2011.

Varela, Mirta "Entre la banalidad y la censura", publicado en www.camouflagecomics.com, consultado online el 20/05/14.

\section{Fuentes:}

Diario Crónica de Comodoro Rivadavia (meses de abril, mayo y junio de 1982).

Diario El Patagónico de Comodoro Rivadavia (meses de abril, mayo y junio de 1982).

Suplemento diario El Patagónico de Comodoro Rivadavia (02 de abril de 2012).

\section{Entrevistas:}

Daniel Alonso, periodista, 24 de febrero de 2013. 